\title{
Evaluation Technology for Wind Power Access in Regional Power Grid Based on PSD-BPA
}

\author{
Jian Bai, Yin Huang, Youjun Wang \\ State Grid Chuzhou Power Supply Company, Anhui, China \\ ayjtxb@163.com
}

Keywords: PSD-BPA, wind power access, regional power grid.

\begin{abstract}
With the large-scale construction of wind farms, the access of the wind farms affects the voltage of regional power grid. Power grid data in the South China region is built on the PSD-BPA system, and the PSD-BPA data of the current region can be obtained from the superior power grid. According to the wind farm planning data, the corresponding data model is established and added to the existing grid data, and the corresponding analysis and calculation are carried out by PSD-BPA software. Taking Chuzhou power grid as an example, the influence of wind power on power system is analyzed.
\end{abstract}

\section{Introduction}

Wind energy, as a renewable resource, has many advantages, such as renewable, no pollution, large reserves, wide distribution and so on. While the cost of wind power is lower than other new energies, technology is also more mature, with large-scale commercial development conditions, and therefore has become an important part of the world's energy.

China's wind power installed capacity continues to grow. In 2014, the national wind power industry continued to maintain strong growth momentum. The annual wind power installed capacity of 19.81GW.New installed capacity hit a record high. Cumulative net installed capacity reached $96.37 \mathrm{GW}$, accounts for $7 \%$ of all power generation capacity, and accounts for $27 \%$ of global wind power.2014 the wind power generates $153400 \mathrm{GWh}$, accounting for $2.78 \%$ of total electricity generation .With the pricing mechanism, the implementation of grid policies, subsidies and the implementation of ultra-high voltage construction has brought about the release of the wind abandon. The wind power installation in the next few years is expected to maintain rapid growth.

The fluctuation of wind power will affect the safe and stable operation of power system. Reasonable evaluation of the influence of wind power on the power system is the premise of reasonable planning.

\section{Influence of wind power access to regional power network}

The wind power will affect the operation stability of the power system, which restricts its large-scale development. The active power of the wind turbine is determined by wind speed. And wind speed has the characteristics of intermittent and random. So the wind power also has the characteristics of randomness and volatility. The randomness and volatility of wind power can cause many negative impacts on the power system.

The fluctuation of the wind power output can cause the voltage, frequency and power fluctuation of the power system. Voltage and frequency fluctuations can cause power quality degradation. Voltage fluctuations are mainly reflected in the impact of the wind power access point voltage. Frequency fluctuations are reflected in the impact on the whole system frequency. The influence of power fluctuation on the transmission system is the change of power flow in the power transmission system, which may cause the overload of the line and the reverse of the power flow . The influence of power fluctuation on power generation system is the need to increase the reserve capacity, so that the power generation system efficiency will be reduced. Large scale wind power acess have a significant impact on the access point voltage. The main performance is caused by the fluctuation of 
active power of power generation, the fluctuation of the voltage in the acess point grows and the stability of the voltage reduces.

The influence of wind power access to the regional power grid is mainly reflected in the influence of the voltage.

The main types of wind power generators are as follows: induction type wind turbine, DFIG(Double-Fed Induction Generator), permanent magnet direct drive wind generator. In operation process of induction type wind power generator, there is a need to absorb reactive power from power system for excitation. The DFIG can realize decoupling control of active and reactive power by adjusting the rotor excitation. Permanent magnet direct drive wind generator through power electronic conversion device is also to achieve the reactive power control.

Induction type wind power generators need to absorb a large number of reactive power from the power system to establish the magnetic field. Generally, reactive power compensation devices need to be installed in the access point. Permanent magnet direct drive wind generator can be controlled by controlling the inverter.The control strategy of the DFIG can be divided into constant power factor control and constant voltage control. For the constant power factor control, the power factor of the DFIG is generally set to be 1 . That is, the wind generator only outputs active power, does not emit reactive power. For the constant voltage control, the terminal voltage of the wind generator is set to be constant. The power factor limit is generally 0.95CA-0.95IND.

The maximum voltage of the wind power access point is considered as the situation that the wind turbine at zero output.The minimum voltage is considered in accordance with the wind power generation at full power. Without considering the action of reactive power compensation device,when the wind turbines don't generate any power at all, the power in the transmission line is the charge power of the transmission line, and the voltage rise is the most significant.And when the wind farm output reaches its maxmum power, the wind power generating units, transformers, line will consume reactive power, at this time the voltage drop is the most significant.

We can use the voltage sensitivity coefficient to measure the level of voltage fluctuation caused by the wind power changes.

The voltage sensitivity coefficient is the ratio of access point voltage change and variation of the output power of the wind farm $\frac{d V}{d P}$. It can be obtained by continuation power flow method.

\section{Overview of PSD-BPA simulation software and its application in China}

BPA computing program is a power system analysis software, which is widely used in the world. PSD-BPA refers to the China characteristic BPA made by the Chinese EPRI electric power system institute through reference of BPA. It's the part of the calculation of the power flow and stability analysis. It have been widely used in power system planning and design, operation and teaching and research departments of electric power system.

The Chinese version was introduced in during 1978-1982. It has been developed into a large commercial power system analysis software package named PSD, which has the power system steady state, electromagnetic transient, electromechanical transient and long-term dynamics, short circuit current, voltage stability and frequency domain calculation. American BPA has terminated the development and maintenance of BPA power flow and transient stability program in 1996.Now only the Chinese EPRI electric power system institute maintains and upgrades Chinese PSD-BPA.

The grid data in the North China region is mostly based on the PSASP program. The data of the South China power grid is mostly built on the basis of PSD-BPA. Power Grid Corp will send related network data to the Regional Power Grid Corp based on the existing power grid operating data and network planning data. In the planning and design, the local Power Grid Corp can add new data to existing systems, and verify its rationality through simulation and calculation. 


\section{Wind farm model construction and mosaic technology}

Wind farm model building bases on the power system construction plan. The wind farm model includes: the model of the wind turbine, the model of the transformer of wind turbine, the model of the transformer of wind farm, the model of the transmission line. When building the wind farm model, wind generators which is connected to the same bus is equivalent to one wind generator, and transformers which is connected to the same bus is equivalent to one transformer.

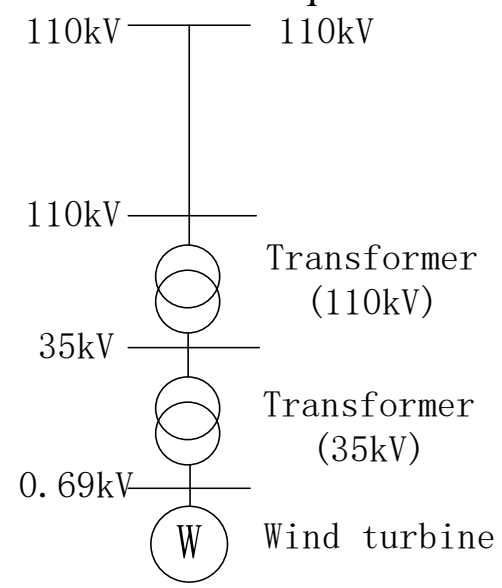

Figure 1 Wind farm model

For the DFIG controlled with the constant power factor, the access point is a PQ point. For the DFIG controlled with the constant voltage, the access point is a PV point.

The input data of PSD-BPA is in the form of data card. The format of the data card can be seen in 《PSD-BPA Power Flow Program User Manual》. Taking Dashan wind farm accessed to Chuzhou power grid as an example. Its main parameters include the type of wind turbine is DFIG, and the total installed capacity of the wind farm is 48.3MW. The control mode of the wind turbine is constant voltage control, and the power factor limits are 0.95CA 0.95IND. The leakage reactance of the transformer for the wind turbine is $6.5 \%$, and the leakage reactance of main transformer for the wind farm is $10.5 \%$.

The new data card data is as following:

BQ AH wandashan11.69 CZ0.0 0.0

B AH wandashan_137 CZ

B AH wandashan $115 \mathrm{CZ}$

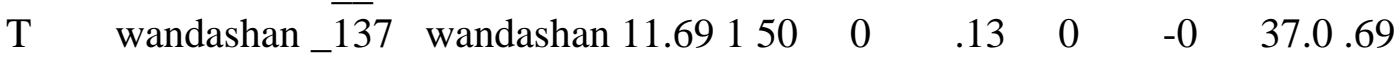

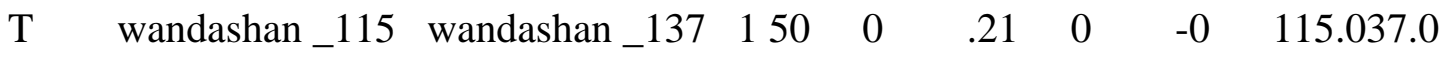

L wandashan_115 guhebian1 $1151600.00177 .00645 \quad .00028$ dagu

After the formation of the data cards, inserted them into the Anhui province network data. Relevant power flow calculation can be carried out.

\section{Simulation}

Taking Chuzhou power grid as an example. Chuzhou is a city in Anhui Province, China. Chuzhou power grid is a part of Lianghuai power grid. It is at the receive-side of the power grid. There is no big power plant in this area. The structure of Chuzhou power grid can be seen as Figure 2. 


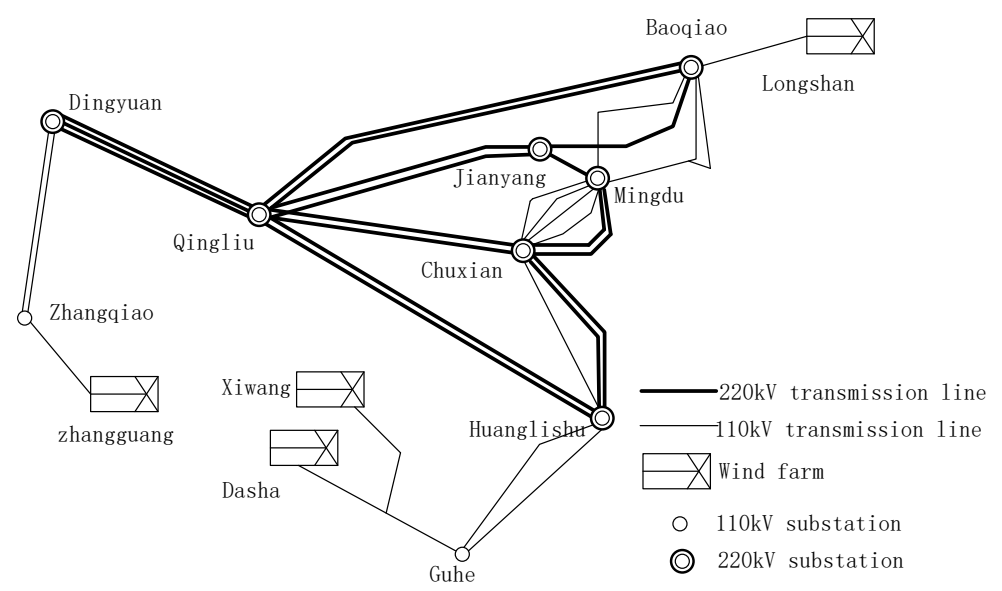

Figure 2 Structure of Chuzhou power grid

In the planning of Chuzhou power grid. New wind fields includs the Dashan wind farm, Xiwang wind farm, Shipei wind farm, Zhangguang wind farm, Longshan wind farm. These wind farms are connected through the $110 \mathrm{kV}$ line access system. Among them, Dashan wind farm and Xiwang wind farm get access to Guhe substation, Zhangguang wind farm get access to Zhangqiao substation, Longshan wind farm get access to Baoqiao substation.

The calculation results are:

Table 1 Voltage deviation of the access bus

\begin{tabular}{|l|l|l|l|}
\hline Name of the Substation & Min voltage (p.u.) & Max voltage (p.u.) & Voltage deviation \\
\hline Guhe substation & 0.993 & 0.999 & $-0.7 \% \sim-0.1 \%$ \\
\hline Zhangqiao substation & 1.037 & 1.058 & $3.7 \% \sim 5.8 \%$ \\
\hline Baoqiao substation & 1.006 & 1.007 & $0.6 \% \sim 0.7 \%$ \\
\hline
\end{tabular}

Table 2 Voltage sensitivity coefficient

\begin{tabular}{|l|l|}
\hline Name & $\frac{d V}{d P}($ p.u./MW) \\
\hline Dawang wind farm & $<0.001$ \\
\hline Xiwang wind farm & $<0.001$ \\
\hline Zhangguang wind farm & 0.001 \\
\hline Longshan wind farm & 0.001 \\
\hline
\end{tabular}

\section{Summary}

In this paper, firstly the influence of wind power access to the regional power network is analyzed, which is mainly reflected in the impact of the access point voltage. Secondly, it is necessary to establish a set of wind power access analysis method based on PSD-BPA, which is based on the PSD-BPA software and its application in China. Then the wind farm model building and mosaic technology, the power grid planning data can be used to create a new data card in PSD-BPA to achieve the combination of new data and the original data. Finally, the rationality of the proposed method is verified by the example of Chuzhou power grid.

\section{References}

[1] YU Delong, ZHAO Haixiang, CAO Na, et al.Analysis of voltage problems caused by wind farms integrating into regional grid[J] China Electric Power, 2006, 39(6):10-14.

[2] SUN Tao, WANG Weisheng, DAI Huizhu, et al.Voltage disturbance and flicker caused by wind power generation[J] Power System Technology, 2003, 27(12):62-66.

[3] ZHANG Liying, YE Tinglu, XIN Yaozhong, et al.Problems and measures of power grid accommodating large scale wind power [J] Proceeding of the CSEE, 2010, 30(25):1-9. 
[4] JIN Haifeng, WU Tao.Voltage stability after grid connection of wind farm[J]. Electric Power Automation Equipment.2010, 30(9):82-84.

[5] XI Xiao, LI Haiyan, KONG Qingdong.Influence of connecting and disconnecting wind farm with regional power network on voltage of the latter[J]. Power System Technology, 2008, 32(10):58-62. 